Elsevier required licence: (C) $<2018>$. This manuscript version is made available under the CC-BY-NC-ND 4.0 license http://creativecommons.org/licenses/bync-nd/4.0/ 


\section{A model for the financial assessment of professional services in community pharmacy: a systematic review}

This paper is a systematic review of the current literature investigating the financial assessment of professional services from a community pharmacy business perspective. Multiple studies, with differing methodologies, that financially assess professional pharmacy services have been identified. From this review we propose a model that provides a structured approach for pharmacists to manage the financial performance of services.

\section{Introduction}

Community pharmacies traditionally combine retail business practices and the delivery of health care, predominantly the supply of pharmaceutical products and services(Hindle 2002). A spectrum of business models, ranging from traditional independent community pharmacies to warehouse discount model pharmacies, exists creating a strong competitive market(Singleton, and Nissen 2014). Economic pressures caused largely by a government policy of reduced dispensing reimbursement and increased discounter type competition, have resulted in an increasing business shift to the provision of services and patient care(Hindle 2002; Singleton, and Nissen 2014; Roberts, Benrimoj, Chen, Williams, Hopp, and Aslani 2005; Rotta, Souza, Salgado, Correr, and FernandezLlimos 2016; Rhodes, Reynolds, Marciniak, and Ferreri 2013; Rogoff, Lee, and Suh 2004). These trends are seen internationally in countries such as the USA, UK, Canada, Australia and New Zealand, where governments are remunerating community pharmacists for the provision of professional pharmacy services(Houle, Grindrod, Chatterley, and Tsuyuki 2014).

Professional pharmacy services are defined as "an action or set of actions undertaken in or organised by a pharmacy, delivered by a pharmacist or other health practitioner, who applies their specialised health knowledge personally or via an intermediary, with a patient/client, population or other health professional, to optimise the process of care, with the aim to improve health outcomes and the value of health care"(Moullin, Sabater-Hernandez, Fernandez-Llimos, and Benrimoj 2013). 
They are provided in addition to the traditional role of dispensing prescriptions and the sale of over the counter medicines (OTCs). These services range from simple activities like providing medicines information, to more complex clinical decision-making services such as prescribing(Benrimoj, Feletto, Gastelurrutia, Martinez-Martinez, and Faus 2010).

There is evidence that the provision of professional pharmacy services has economic, humanistic and clinical benefits for both patients and national healthcare systems(Cranor, Bunting, and Christensen 2003; Cranor, and Christensen 2003; Jodar-Sanchez, Malet-Larrea, Martin, GarciaMochon, Lopez Del Amo, Martinez-Martinez, Gastelurrutia-Garralda, Garcia-Cardenas, SabaterHernandez, Saez-Benito, and Benrimoj 2015; Machado, Bajcar, Guzzo, and Einarson 2007). Furthermore, by delivering professional services, community pharmacies are able to differentiate from internal and external competitors and add another source of income(Singleton, and Nissen 2014; Rhodes, Reynolds, Marciniak, and Ferreri 2013; Houle, Grindrod, Chatterley, and Tsuyuki 2014). However, implementation of services into routine practice is limited. Different barriers have been described, including the lack of evidence-based implementation programs that address the economic and financial analysis from a business owner perspective(Lounsbery, Green, Bennett, and Pedersen 2009; Elrod, Synder, Hall, Mcgivney, and Smith 2012). In fact, only a limited number of studies have assessed the financial benefit of professional services to the community pharmacy as a business(Rhodes, Reynolds, Marciniak, and Ferreri 2013; Boyle, Coffey, and Palmer 2004; Cerulli, and Zeolla 2004; Doucette, McDonough, Mormann, Vaschevici, Urmie, and Patterson 2012; Gazda, Berenbrok, and Ferreri 2016; Gregorio, Russo, and Lapao 2015; Hedden, Kuehl, and Liu 2014; Houle, Chuck, and Tsuyuki 2012; Kent, McDonough, Dinges, and Doucette 2006; Lasota 2015; Lecher, Shrestha, Botts, Alvarez, Moore, Thomas, and Weidle 2015; Liu, Nevins, Carruthers, Doucette, McDonough, and Pan 2007; McDonough, Harthan, McLeese, and Doucette 2010; Melody, Shah, Patel, and Willey 2015; Norwood, Sleath, Caiola, and Lien 1998; Riley 2013; Rupp 2011; Wilson, Osterhaus, Farris, Doucette, Currie, Bullock, and Kumbera 2005; Wood, McDonough, and Doucette 2009; Pudlo 2011; Rieck 2006). These studies are crucial in developing an insight into the financial, 
long-term sustainability of professional pharmacy services and expand their broader implementation. Consequently, the objectives of this systematic review are to identify measures and indicators used to assess financial performance of professional services in community pharmacy and to develop a model to financially assess professional services in community pharmacy.

\section{Methods}

This systematic review follows PRISMA and AMSTAR recommended methods and reporting standards(Liberati, Altman, Tetzlaff, Mulrow, Gotzsche, loannidis, Clarke, Devereaux, Kleijnen, and Moher 2009) (Shea, Grimshaw, Wells, Boers, Andersson, Hamel, Porter, Tugwell, Moher, and Bouter 2007). The literature search was undertaken in March 2016 in PubMed and Scopus (Table 1). A grey literature search was also performed in Google.com. Publication type and date filters were not applied to the search. The references of the included papers were reviewed for other relevant studies. Duplicated records were removed.

\section{Table 1}

\section{Search strategies used in systematic review literature search.}

\section{Table 2}

\section{Google Search: terms used in systematic review grey literature search.}

The identification of relevant records was undertaken by two experts on the financial aspects of professional services (F.F-L and S.Z). Firstly, the title and abstract of records retrieved were screened for applicability, which was over-inclusive. Studies written in a language other than English, Spanish, Italian, French and Portuguese were discarded. Secondly, full text-records not discarded in the first screening were reviewed against the following exclusion criteria: 1) Literature Reviews, 2) Studies not reporting quantitative financial data from community pharmacy, 3) Studies not assessing a professional pharmacy service according to the Moullin et al. (2013) definition 4) 
Studies lacking a methodology for the measurement and assessment of financial outcomes, 5) Costeffectiveness analysis, cost-utility analysis or cost-benefit analysis studies were excluded as they did not include data that was related to the pharmacy business.

Using a piloted data extraction form the following information was collected: 1) Title, author, journal, date, page number, country and contact details. 2) Date and duration of data collection. 3) Objective. 4) Method of data collection and calculation. 5) Sensitivity analysis. 6) Currency, Limitations for cost/revenue/method of data collection/method of calculation. 8) Standardised currency value for the results reported. 9) Conclusion. 10) Professional services: number assessed, type of service (product related vs. test based), name of services, nature of services (classified according to the Hierarchical Model(Benrimoj, Feletto, Gastelurrutia, MartinezMartinez, and Faus 2010)), implementation stage reported, financial result (nature and amount), frequency of service, costs (indirect/direct and fixed/variable/semi-variable), sources of revenue (patient/insurance/government), net total cost, net total revenue, break-even point, break-even price, net profit/loss. 11) Participant pharmacies: number and type of pharmacies. 12) Service portfolio: total revenue, total costs, overall financial result.

All monetary results were standardised to 2015 US Dollars using the 'CCEMG - EPPI-Centre Cost Converter' (v.1.5 last update: 29 April 2016)(Shemilt, Thomas, and Marcello 2010). In this paper the \$ symbol will hereafter be in reference to USD 2015.

\section{Model Development}

In order to develop the model for the financial assessment of professional services in community pharmacy, extraction of all relevant financial data was necessary. These included a range of financial measures such as costs, revenue and breakeven point, where costs were segmented into six types (as defined in supplementary material table 2) and revenue was categorised as government, health insurance or patient funded. Performance indicators such as Return on 
Investment (ROI) and Net Profit/Loss were identified with supporting external resources and extracted(Langfield-Smith 2015). The stage of implementation as defined by Moullin et al. (2016) was also used to categorise papers(Moullin, Sabater-Hernandez, and Benrimoj 2016). This was primarily based upon the duration of the provision of the service in the pharmacy being investigated.

\section{Results}

A total of 1291 articles and 121 documents of grey literature were identified. Following screening of article titles and abstracts, 1171 articles were excluded. Of the remaining 120 articles, four were excluded as they were literature reviews, 58 were excluded for not reporting quantitative financial data from community pharmacies, 21 were excluded for not assessing professional pharmacy services, 45 were excluded for lacking a methodology for measurement and assessment of financial outcomes and two were excluded as they were cost-effectiveness analysis or cost-utility analysis or cost-benefit analysis studies (Figure 1). Finally, 21 studies were included in the review.

\section{Figure 1}

\section{Flow diagram of studies included in the review.}

Of the 21 studies, 17 had been undertaken in the USA(Rhodes, Reynolds, Marciniak, and Ferreri 2013; Boyle, Coffey, and Palmer 2004; Cerulli, and Zeolla 2004; Doucette, McDonough, Mormann, Vaschevici, Urmie, and Patterson 2012; Gazda, Berenbrok, and Ferreri 2016; Hedden, Kuehl, and Liu 2014; Kent, McDonough, Dinges, and Doucette 2006; Lecher, Shrestha, Botts, Alvarez, Moore, Thomas, and Weidle 2015; Liu, Nevins, Carruthers, Doucette, McDonough, and Pan 2007; McDonough, Harthan, McLeese, and Doucette 2010; Melody, Shah, Patel, and Willey 2015; Norwood, Sleath, Caiola, and Lien 1998; Rupp 2011; Wilson, Osterhaus, Farris, Doucette, Currie, Bullock, and Kumbera 2005; Wood, McDonough, and Doucette 2009), two in Canada(Houle, Chuck, and Tsuyuki 2012; Riley 2013), one in Portugal(Gregorio, Russo, and Lapao 2015) and one in Australia(Rieck 2006). The years of publication ranged from 1998 to 2016. Four studies were set in 
franchised community pharmacies(Rhodes, Reynolds, Marciniak, and Ferreri 2013; Gazda, Berenbrok, and Ferreri 2016; Hedden, Kuehl, and Liu 2014; Lasota 2015), eight in independent community pharmacies(Doucette, McDonough, Mormann, Vaschevici, Urmie, and Patterson 2012; Kent, McDonough, Dinges, and Doucette 2006; Liu, Nevins, Carruthers, Doucette, McDonough, and Pan 2007; McDonough, Harthan, McLeese, and Doucette 2010; Melody, Shah, Patel, and Willey 2015; Rupp 2011; Wilson, Osterhaus, Farris, Doucette, Currie, Bullock, and Kumbera 2005; Wood, McDonough, and Doucette 2009), four were set in a combination of franchised and independent pharmacies(Boyle, Coffey, and Palmer 2004; Cerulli, and Zeolla 2004; Lecher, Shrestha, Botts, Alvarez, Moore, Thomas, and Weidle 2015; Norwood, Sleath, Caiola, and Lien 1998) and five studies were unspecified in the type of community pharmacy setting(Gregorio, Russo, and Lapao 2015; Houle, Chuck, and Tsuyuki 2012; Riley 2013; Pudlo 2011; Rieck 2006).

The majority of studies financially assessed only one professional service(Rhodes, Reynolds, Marciniak, and Ferreri 2013; Boyle, Coffey, and Palmer 2004; Cerulli, and Zeolla 2004; Gazda, Berenbrok, and Ferreri 2016; Gregorio, Russo, and Lapao 2015; Hedden, Kuehl, and Liu 2014; Lecher, Shrestha, Botts, Alvarez, Moore, Thomas, and Weidle 2015; Liu, Nevins, Carruthers, Doucette, McDonough, and Pan 2007; McDonough, Harthan, McLeese, and Doucette 2010; Melody, Shah, Patel, and Willey 2015; Rupp 2011; Wilson, Osterhaus, Farris, Doucette, Currie, Bullock, and Kumbera 2005; Wood, McDonough, and Doucette 2009; Pudlo 2011; Rieck 2006). Three studies assessed between two and five services(Houle, Chuck, and Tsuyuki 2012; Lasota 2015; Riley 2013), one examined six to 10 services (Kent, McDonough, Dinges, and Doucette 2006) and two financially assessed more than 10 services(Doucette, McDonough, Mormann, Vaschevici, Urmie, and Patterson 2012; Norwood, Sleath, Caiola, and Lien 1998). A full definition for the most common professional services reported can be found in the supplementary material table 1.

Medication Therapy Management (MTM) services were the most commonly financially evaluated service; assessed in 10 of the studies(Rhodes, Reynolds, Marciniak, and Ferreri 2013; 
Doucette, McDonough, Mormann, Vaschevici, Urmie, and Patterson 2012; Gazda, Berenbrok, and Ferreri 2016; Houle, Chuck, and Tsuyuki 2012; Lasota 2015; McDonough, Harthan, McLeese, and Doucette 2010; Melody, Shah, Patel, and Willey 2015; Riley 2013; Rupp 2011; Pudlo 2011). Four of the 10 papers investigating MTM services reported a net financial benefit or net gain from the service(Doucette, McDonough, Mormann, Vaschevici, Urmie, and Patterson 2012; Gazda, Berenbrok, and Ferreri 2016; McDonough, Harthan, McLeese, and Doucette 2010; Pudlo 2011), with one paper reporting a negative return on investment(Rhodes, Reynolds, Marciniak, and Ferreri 2013). The remaining four papers did not report any overall financial appraisal but rather focused on either costs or revenues, or both but without further evaluation(Houle, Chuck, and Tsuyuki 2012; Lasota 2015; Melody, Shah, Patel, and Willey 2015; Riley 2013).

Eleven papers investigated test-based services, which include disease screening and disease prevention services(Boyle, Coffey, and Palmer 2004; Cerulli, and Zeolla 2004; Doucette, McDonough, Mormann, Vaschevici, Urmie, and Patterson 2012; Gregorio, Russo, and Lapao 2015; Kent, McDonough, Dinges, and Doucette 2006; Lecher, Shrestha, Botts, Alvarez, Moore, Thomas, and Weidle 2015; Liu, Nevins, Carruthers, Doucette, McDonough, and Pan 2007; Norwood, Sleath, Caiola, and Lien 1998; Riley 2013; Wilson, Osterhaus, Farris, Doucette, Currie, Bullock, and Kumbera 2005; Rieck 2006). Direct variable costs were the most reported costs for these services(Riley 2013). Five studies reported a net financial gain or profit from the analysis(Doucette, McDonough, Mormann, Vaschevici, Urmie, and Patterson 2012; Kent, McDonough, Dinges, and Doucette 2006; Liu, Nevins, Carruthers, Doucette, McDonough, and Pan 2007; Wilson, Osterhaus, Farris, Doucette, Currie, Bullock, and Kumbera 2005; Rieck 2006).

Three of the USA papers assessed vaccination services, namely influenza, pneumococcal and herpes zoster(Doucette, McDonough, Mormann, Vaschevici, Urmie, and Patterson 2012; Hedden, Kuehl, and Liu 2014; Wood, McDonough, and Doucette 2009). Total revenue and total costs were reported for all studies. A mixture of patient and insurance payment was the main sources of 
revenue for vaccination services(Doucette, McDonough, Mormann, Vaschevici, Urmie, and Patterson 2012; Hedden, Kuehl, and Liu 2014; Wood, McDonough, and Doucette 2009). Direct fixed, direct variable and indirect fixed costs were measured in all of the vaccination studies(Doucette, McDonough, Mormann, Vaschevici, Urmie, and Patterson 2012; Hedden, Kuehl, and Liu 2014; Wood, McDonough, and Doucette 2009). All studies reported a net financial gain or profit from delivering the service, except for 2 years of a 3 year study assessing pneumococcal vaccination which reported a net loss attributed to the increased cost of the vaccine(Doucette, McDonough, Mormann, Vaschevici, Urmie, and Patterson 2012; Hedden, Kuehl, and Liu 2014; Wood, McDonough, and Doucette 2009).

As per Moullin et al. (2016)(Moullin, Sabater-Hernandez, and Benrimoj 2016), 14 papers investigated services at the preparation, testing and maintenance phases of the implementation cycle(Rhodes, Reynolds, Marciniak, and Ferreri 2013; Boyle, Coffey, and Palmer 2004; Cerulli, and Zeolla 2004; Hedden, Kuehl, and Liu 2014; Houle, Chuck, and Tsuyuki 2012; Lasota 2015; Lecher, Shrestha, Botts, Alvarez, Moore, Thomas, and Weidle 2015; Melody, Shah, Patel, and Willey 2015; Norwood, Sleath, Caiola, and Lien 1998; Riley 2013; Wilson, Osterhaus, Farris, Doucette, Currie, Bullock, and Kumbera 2005; Wood, McDonough, and Doucette 2009; Pudlo 2011; Rieck 2006). Only seven papers investigated services at sustainability(Doucette, McDonough, Mormann, Vaschevici, Urmie, and Patterson 2012; Gazda, Berenbrok, and Ferreri 2016; Gregorio, Russo, and Lapao 2015; Kent, McDonough, Dinges, and Doucette 2006; Liu, Nevins, Carruthers, Doucette, McDonough, and Pan 2007; McDonough, Harthan, McLeese, and Doucette 2010; Rupp 2011).

\section{Financial Measures}

Costs

Cost was the financial measure most commonly reported. The types of costs reported in the studies were total, direct variable, direct fixed, direct semi-variable and indirect fixed costs. Indirect 
variable and indirect semi-variable costs were not reported in any of the studies included. Three papers only measured costs in their financial assessment as the sole measure (Gregorio, Russo, and Lapao 2015; Lecher, Shrestha, Botts, Alvarez, Moore, Thomas, and Weidle 2015; Rupp 2011).

Sixteen studies reported a total cost for delivering the service(Rhodes, Reynolds, Marciniak, and Ferreri 2013; Cerulli, and Zeolla 2004; Doucette, McDonough, Mormann, Vaschevici, Urmie, and Patterson 2012; Gazda, Berenbrok, and Ferreri 2016; Gregorio, Russo, and Lapao 2015; Hedden, Kuehl, and Liu 2014; Kent, McDonough, Dinges, and Doucette 2006; Lecher, Shrestha, Botts, Alvarez, Moore, Thomas, and Weidle 2015; Liu, Nevins, Carruthers, Doucette, McDonough, and Pan 2007; McDonough, Harthan, McLeese, and Doucette 2010; Norwood, Sleath, Caiola, and Lien 1998; Rupp 2011; Wilson, Osterhaus, Farris, Doucette, Currie, Bullock, and Kumbera 2005; Wood, McDonough, and Doucette 2009; Pudlo 2011; Rieck 2006). This was reported in four different ways, which included cost per service, cost per patient, cost per service over a period of time and cost per service provider. For example, Gregorio et al. (2015) reported the average total cost per health screening service (see supplementary material table 1 ) delivered at $\$ 5.58$ (Gregorio, Russo, and Lapao 2015). Lecher et al. (2015) calculated the total cost to deliver HIV testing at $\$ 48.97$ per patient(Lecher, Shrestha, Botts, Alvarez, Moore, Thomas, and Weidle 2015). Most authors reported the total cost of delivering a service over a period of time(Rhodes, Reynolds, Marciniak, and Ferreri 2013; Cerulli, and Zeolla 2004; Doucette, McDonough, Mormann, Vaschevici, Urmie, and Patterson 2012; Gazda, Berenbrok, and Ferreri 2016; Hedden, Kuehl, and Liu 2014; Kent, McDonough, Dinges, and Doucette 2006; Liu, Nevins, Carruthers, Doucette, McDonough, and Pan 2007; McDonough, Harthan, McLeese, and Doucette 2010; Melody, Shah, Patel, and Willey 2015; Norwood, Sleath, Caiola, and Lien 1998; Wilson, Osterhaus, Farris, Doucette, Currie, Bullock, and Kumbera 2005; Wood, McDonough, and Doucette 2009). For example Wood et al. (2009) reported a total cost of $\$ 91248.32$ for delivering a herpes zoster vaccination service to 478 patients over 11 months in an independent community pharmacy, where the cost of the vaccine contributed to the total cost of the service(Wood, McDonough, and Doucette 2009). Liu et al. (2007) reported the total costs of an osteoporosis 
screening service delivered to 444 women over 48 months dependant on the provider delivering the service, where with a pharmacist delivering the service the total cost was $\$ 12734.95$, resident total cost was $\$ 8245.70$ and a combination of pharmacist and resident the total cost was $\$ 10490.32$ (Liu, Nevins, Carruthers, Doucette, McDonough, and Pan 2007).

Seventeen studies reported direct variable costs(Rhodes, Reynolds, Marciniak, and Ferreri 2013; Boyle, Coffey, and Palmer 2004; Cerulli, and Zeolla 2004; Doucette, McDonough, Mormann, Vaschevici, Urmie, and Patterson 2012; Gazda, Berenbrok, and Ferreri 2016; Gregorio, Russo, and Lapao 2015; Hedden, Kuehl, and Liu 2014; Kent, McDonough, Dinges, and Doucette 2006; Lecher, Shrestha, Botts, Alvarez, Moore, Thomas, and Weidle 2015; Liu, Nevins, Carruthers, Doucette, McDonough, and Pan 2007; McDonough, Harthan, McLeese, and Doucette 2010; Norwood, Sleath, Caiola, and Lien 1998; Rupp 2011; Wilson, Osterhaus, Farris, Doucette, Currie, Bullock, and Kumbera 2005; Wood, McDonough, and Doucette 2009; Pudlo 2011; Rieck 2006) which included labour, medications (e.g. vaccines), materials and supplies, administrative costs and rent. Fifteen of the 21 studies measured the cost of labour for the services being assessed(Rhodes, Reynolds, Marciniak, and Ferreri 2013; Boyle, Coffey, and Palmer 2004; Cerulli, and Zeolla 2004; Doucette, McDonough, Mormann, Vaschevici, Urmie, and Patterson 2012; Gazda, Berenbrok, and Ferreri 2016; Hedden, Kuehl, and Liu 2014; Kent, McDonough, Dinges, and Doucette 2006; Lecher, Shrestha, Botts, Alvarez, Moore, Thomas, and Weidle 2015; Liu, Nevins, Carruthers, Doucette, McDonough, and Pan 2007; McDonough, Harthan, McLeese, and Doucette 2010; Rupp 2011; Wilson, Osterhaus, Farris, Doucette, Currie, Bullock, and Kumbera 2005; Wood, McDonough, and Doucette 2009; Pudlo 2011; Rieck 2006). To estimate labour costs, time for the provision of the service was mainly collected through estimated self-reporting and/or estimated questionnaire responses(Rhodes, Reynolds, Marciniak, and Ferreri 2013; Boyle, Coffey, and Palmer 2004; Cerulli, and Zeolla 2004; Doucette, McDonough, Mormann, Vaschevici, Urmie, and Patterson 2012; Gazda, Berenbrok, and Ferreri 2016; Hedden, Kuehl, and Liu 2014; Kent, McDonough, Dinges, and Doucette 2006; Lecher, Shrestha, Botts, Alvarez, Moore, Thomas, and Weidle 2015; Liu, Nevins, Carruthers, Doucette, McDonough, and Pan 
2007; McDonough, Harthan, McLeese, and Doucette 2010; Rupp 2011; Wilson, Osterhaus, Farris, Doucette, Currie, Bullock, and Kumbera 2005; Wood, McDonough, and Doucette 2009; Pudlo 2011; Rieck 2006). The hourly rate of pharmacist or technician wages was either collected directly from the pharmacy or from the governing institutions. Labour costs were reported it in 2 different ways, per unit of service delivered or as a total cost for the service over a period of time. Rupp et al. (2011) calculated the cost of labour per unit of service delivered at $\$ 20.51$ per MTM service(Rupp 2011). While Gazda et al. (2016) calculated the total cost of labour for 76 pharmacies delivering MTM services to 13730 patients over a 12 month period at $\$ 304624.58$ (Gazda, Berenbrok, and Ferreri 2016).

Direct fixed costs were reported in 13 of the studies(Rhodes, Reynolds, Marciniak, and Ferreri 2013; Cerulli, and Zeolla 2004; Doucette, McDonough, Mormann, Vaschevici, Urmie, and Patterson 2012; Hedden, Kuehl, and Liu 2014; Kent, McDonough, Dinges, and Doucette 2006; Lecher, Shrestha, Botts, Alvarez, Moore, Thomas, and Weidle 2015; Liu, Nevins, Carruthers, Doucette, McDonough, and Pan 2007; McDonough, Harthan, McLeese, and Doucette 2010; Norwood, Sleath, Caiola, and Lien 1998; Rupp 2011; Wilson, Osterhaus, Farris, Doucette, Currie, Bullock, and Kumbera 2005; Wood, McDonough, and Doucette 2009; Rieck 2006). The most commonly investigated direct fixed costs included training, marketing and equipment. Other direct fixed costs included service development, remodelling, travel and program administration. Direct fixed costs were reported individually per unit of service delivered for example, Rupp et al. (2016) calculated equipment costs to be $\$ 2.05$ and software, marketing and promotion at $\$ 8.23$ per MTM service(Rupp 2011). Direct fixed costs were also reported as a total for the pharmacy over a given period of time, for example Norwood et al. (1998) calculated the overall direct fixed costs, which included education, remodelling, equipment and furniture, scientific instruments, consulting/ franchise, marketing and miscellaneous, on average for each pharmacy to be $\$ 48302.69$ annually for a disease management service(Norwood, Sleath, Caiola, and Lien 1998). 
Direct semi-variable costs were reported in two papers(Doucette, McDonough, Mormann, Vaschevici, Urmie, and Patterson 2012; Norwood, Sleath, Caiola, and Lien 1998). Doucette et al. (2012) reported these costs for an influenza vaccination service and a herpes zoster vaccination service. The direct semi variable costs for the influenza vaccination service measured were under the title "miscellaneous", which involved the cost of the pharmacist resubmitting paper claims and entering information into the Immunisation Registry Information System and were reported per year of the study, as $\$ 132.00$ in 2008 for 352 patients, $\$ 132.00$ in 2009 for 664 patients and $\$ 198.00$ in 2010 for 852 patients(Doucette, McDonough, Mormann, Vaschevici, Urmie, and Patterson 2012). For the herpes zoster vaccination service the direct semi-variable costs included the costs associated with faxing patients' physicians to alert them that the patient had received the vaccine and were also reported per year of the study as $\$ 103.57$ in 2008 for 271 patients, \$92.51 in 2009 for 178 patients and \$83.34 in 2010 for 104 patients(Doucette, McDonough, Mormann, Vaschevici, Urmie, and Patterson 2012). Norwood et al. (1998) measured the direct semi-variable cost for all personnel hired to implement new disease management services in 8 pharmacies including smoking cessation, pain management, asthma, diabetes and hypertension. This was calculated as $\$ 48,553.74$, which is a total for all services in all pharmacies(Norwood, Sleath, Caiola, and Lien 1998).

Six papers reported indirect fixed costs(Doucette, McDonough, Mormann, Vaschevici, Urmie, and Patterson 2012; Hedden, Kuehl, and Liu 2014; Kent, McDonough, Dinges, and Doucette 2006; Rupp 2011; Wood, McDonough, and Doucette 2009; Rieck 2006). The most commonly reported indirect fixed costs were overhead costs. In one study overheads included the total of rent, utilities and insurance and was reported as $\$ 0.52$ per MTM service(Rupp 2011). Rieck et al. (2006) included space in the pharmacy, marketing, additional administration and paper work when calculating overheads for a weight management service, which was reported at $\$ 1728.81$ for an average of 30 patients per pharmacy annually(Rieck 2006). Hedden et al. (2014) reported the overheads for a herpes zoster vaccination service as $\$ 1117.92$ for 19 pharmacies over 5 months, which was calculated by determining the percentage of herpes zoster vaccine prescriptions to total 
prescriptions and multiplying it by the space of the pharmacy and utilities(Hedden, Kuehl, and Liu 2014).

Revenue

Revenue was classified as government funded, patient funded or insurance funded. Four papers only reported revenue in their financial assessment(Houle, Chuck, and Tsuyuki 2012; Lasota 2015; Melody, Shah, Patel, and Willey 2015; Riley 2013).

Total revenue was calculated in 16 papers and reported in different ways(Rhodes, Reynolds, Marciniak, and Ferreri 2013; Doucette, McDonough, Mormann, Vaschevici, Urmie, and Patterson 2012; Gazda, Berenbrok, and Ferreri 2016; Hedden, Kuehl, and Liu 2014; Houle, Chuck, and Tsuyuki 2012; Kent, McDonough, Dinges, and Doucette 2006; Lasota 2015; Liu, Nevins, Carruthers, Doucette, McDonough, and Pan 2007; McDonough, Harthan, McLeese, and Doucette 2010; Melody, Shah, Patel, and Willey 2015; Norwood, Sleath, Caiola, and Lien 1998; Riley 2013; Wilson, Osterhaus, Farris, Doucette, Currie, Bullock, and Kumbera 2005; Wood, McDonough, and Doucette 2009; Pudlo 2011; Rieck 2006). Riley (2013) calculated the total revenue for one pharmacy of a smoking cessation service at $\$ 135.64$ over 4 months for 2 patients who received initial, first follow-up and second follow-up appointments(Riley 2013). Whereas, Hedden et al. (2014) reported the total revenue for 19 pharmacies delivering a herpes zoster vaccination service over 5 months to 662 patients as \$126265.95(Hedden, Kuehl, and Liu 2014). Alternatively, total revenue was reported per service delivered. This is seen in Boyle et al. (2004) where total revenue was reported per Men's Health Risk Assessment Tool (MHRAT) service delivered as $\$ 5.46$ (Boyle, Coffey, and Palmer 2004).

Most services were government funded(Rhodes, Reynolds, Marciniak, and Ferreri 2013; Boyle, Coffey, and Palmer 2004; Gazda, Berenbrok, and Ferreri 2016; Houle, Chuck, and Tsuyuki 2012; Kent, McDonough, Dinges, and Doucette 2006; Liu, Nevins, Carruthers, Doucette, McDonough, and Pan 2007; McDonough, Harthan, McLeese, and Doucette 2010; Riley 2013; Pudlo 2011; Rieck 
2006) with the majority being fee per service such as in Riley (2013) where $\$ 127.75$ was paid per MTM service(Riley 2013). Some services were paid for performance, where a particular health result or acceptance from a health care professional would determine the amount paid(Rhodes, Reynolds, Marciniak, and Ferreri 2013; Gazda, Berenbrok, and Ferreri 2016; Lasota 2015; Melody, Shah, Patel, and Willey 2015; Pudlo 2011). This was seen with Melody et al. (2015), Rhodes et al. (2013) and Gazda et al. (2016) where targeted medication reviews were reimbursed up to $\$ 20$ based upon the health outcomes of indication/efficacy/safety and $\$ 2.18$ when refused by the patient or presctiber(Rhodes, Reynolds, Marciniak, and Ferreri 2013; Gazda, Berenbrok, and Ferreri 2016; Melody, Shah, Patel, and Willey 2015). Payment based on initial/follow-up and different types of consults with a maximum per calendar year were also reported(Houle, Chuck, and Tsuyuki 2012; McDonough, Harthan, McLeese, and Doucette 2010; Riley 2013). For example, a study in lowa City, USA reported a patient fee for MedsCheck of $\$ 85.07$ for initial and $\$ 45.37$ for follow-up consults(McDonough, Harthan, McLeese, and Doucette 2010). Whereas Houle et al. (2012) reported a reimbursement from the Ontario government of $\$ 53.64$ per MedsCheck service per patient per annum(Houle, Chuck, and Tsuyuki 2012). Capitation fee was reported in Rieck et al. (2006) at a rate of $\$ 86.44$ per client per annum for a maximum of 30 patients(Rieck 2006), and Wilson et al. (2005) at a rate of $\$ 43.89$ per patient per month for "Heart Smart" service regardless of whether the patient was seen with up to 8 visits per annum(Wilson, Osterhaus, Farris, Doucette, Currie, Bullock, and Kumbera 2005).

Six articles reported patient payment as a source of revenue for the services delivered(Cerulli, and Zeolla 2004; Hedden, Kuehl, and Liu 2014; McDonough, Harthan, McLeese, and Doucette 2010; Riley 2013; Wood, McDonough, and Doucette 2009; Rieck 2006). Of the six articles, four studies gave a value for revenue(Cerulli, and Zeolla 2004; McDonough, Harthan, McLeese, and Doucette 2010; Wood, McDonough, and Doucette 2009; Rieck 2006). McDonough et al. (2010) reported a direct patient payment for MedsCheck, with initial visits generating \$85.07 and follow-up visits $\$ 45.37$ (McDonough, Harthan, McLeese, and Doucette 2010). Cerulli et al. (2004) 
calculated the revenue generated with a direct patient payment of $\$ 30.79$ per 30 minute consult for a bone mineral density screening and education program(Cerulli, and Zeolla 2004). Another form of patient payment was a fee per annum to access the service which was reported in Rieck et al. (2006) where patients paid $\$ 432.20$ per client per annum for a weight loss program(Rieck 2006). In one study a proportion of patients paid for a herpes zoster vaccination service at $\$ 218.06$ per vaccination, while others had to pay a proportion that wasn't covered by their insurance company at an average of $\$ 92.74$ (SD: $\pm \$ 67.10)$ (Wood, McDonough, and Doucette 2009).

The level of reimbursement from insurance companies varied(Lasota 2015; Melody, Shah, Patel, and Willey 2015; Wilson, Osterhaus, Farris, Doucette, Currie, Bullock, and Kumbera 2005; Wood, McDonough, and Doucette 2009). Targeted Medication Intervention (TMI) was reimbursed between $\$ 10.37$ and $\$ 956.28$ dependent upon the category of the TMI and whether the intervention was accepted or rejected(Melody, Shah, Patel, and Willey 2015). Lasota et al. (2015) reported a Targeted Intervention Program, delivered as part of medication management service for 36 patients, generated $\$ 393.22$ revenue in insurance claims over 1 month in a pharmacy(Lasota 2015). A study of a 12 month cardiovascular wellness program in a community pharmacy reported revenue of $\$ 5646.24$ for the initial and advanced screening of 96 patients and \$16416.94 in ongoing Heart Smart registration fees for 36 patients which were reimbursed monthly(Wilson, Osterhaus, Farris, Doucette, Currie, Bullock, and Kumbera 2005). Herpes zoster vaccination achieved between $\$ 48.19$ and $\$ 137.06$ per patient, which represented 24 percent to 65 percent complete reimbursement respectively(Wood, McDonough, and Doucette 2009).

Only one paper measured indirect sources of revenue when calculating the financial performance of a MedsCheck(Riley 2013). The sale of replaced expired stock, adherence aids and other testing equipment contributed to the total revenue generated of $\$ 29320.43$ over 4 months for 363 MedsChecks(Riley 2013).

\section{Breakeven point}


Breakeven point was reported in six studies and expressed as a point in time or as a number of services to be delivered or as a number of patients to receive the service at a certain revenue(Rhodes, Reynolds, Marciniak, and Ferreri 2013; Cerulli, and Zeolla 2004; Hedden, Kuehl, and Liu 2014; McDonough, Harthan, McLeese, and Doucette 2010; Rupp 2011; Rieck 2006). Rhodes et al. (2013) calculated the breakeven point for the time to deliver a targeted medication intervention program (see supplementary material table 1 ) as 21.85 minutes or less at a pharmacist wage of $\$ 57.19$ per hour and total revenue of $\$ 16597.32$ (Rhodes, Reynolds, Marciniak, and Ferreri 2013). Hedden et al. (2014), calculated the breakeven point for a herpes zoster vaccination service under two scenarios, where all possible expenses were considered (broad model) versus only those that the pharmacies actually recorded (localised model)(Hedden, Kuehl, and Liu 2014). The broad model generating an average profit of $\$ 10.27$ per vaccine required 320 vaccines for the service to breakeven, whilst the localised model generating an average profit of $\$ 30.35$ per vaccine required only 14 vaccines to breakeven(Hedden, Kuehl, and Liu 2014). McDonough et al. (2010), reported a 16 month breakeven point for an MTM service(McDonough, Harthan, McLeese, and Doucette 2010). Cerulli et al. (2004) calculated that 37 Bone Mineral Density (BMD) screenings per day at $\$ 25$ per patient would breakeven by 35 days or at $\$ 30$ per patient, 24 days(Cerulli, and Zeolla 2004). Rupp (2011) reported the breakeven point as both the number of services to be delivered and as a point in time, where at a revenue of $\$ 53.49$ per medication therapy management service called MediMax, a volume of 42.7 units would be required to breakeven, or at two services per week calculated a breakeven point of 22 weeks. Rieck et al. (2006) forecasted the breakeven point for a pharmacy weight management program of seven months assuming 30 patients enrolled in the program per annum, an annual price to the patient of $\$ 432.20$ and government subsidy of $\$ 86.44$ per patient(Rieck 2006).

\section{Performance Indicators}

Return On Investment (ROI) 
Return On Investment (ROI) was reported in two ways, either as a percentage or as a dollar figure. Two studies in North Carolina USA expressed ROI as a percentage. Rhodes et al. (2013) reported a ROI of negative 3 per cent over 6 months for 797 claims of a Medication Intervention Program service(Rhodes, Reynolds, Marciniak, and Ferreri 2013). Gazda et al. (2016) reported ROI as a percentage and dollar figure, where a hub and spoke model of a Medication Therapy Management service delivered generated a ROI of 4.6 per cent or $\$ 8290.74$ when $\$ 180957.52$ was invested in pharmacists wages, whereas an integrated model generated a ROI of 7.9 per cent or $\$ 24076.70$ when $\$ 304624.58$ was invested in pharmacists wages(Gazda, Berenbrok, and Ferreri 2016).

\section{Net Profit}

Net profit was also described as net benefit, net gain, net daily revenue or increase in EBIT (Expenses Before Interest and Tax) and ranged between $\$ 3.72$ over 16 months for 191 MTM services delivered in a pharmacy(McDonough, Harthan, McLeese, and Doucette 2010) and \$20093.65 over 5 months for a herpes zoster vaccination service delivered to 662 patients between 19 pharmacies(Cerulli, and Zeolla 2004; Doucette, McDonough, Mormann, Vaschevici, Urmie, and Patterson 2012; Hedden, Kuehl, and Liu 2014; Kent, McDonough, Dinges, and Doucette 2006; McDonough, Harthan, McLeese, and Doucette 2010; Wilson, Osterhaus, Farris, Doucette, Currie, Bullock, and Kumbera 2005; Wood, McDonough, and Doucette 2009; Pudlo 2011; Rieck 2006).

Five of the papers assessed profitability using a sensitivity analysis(Cerulli, and Zeolla 2004; Hedden, Kuehl, and Liu 2014; Kent, McDonough, Dinges, and Doucette 2006; McDonough, Harthan, McLeese, and Doucette 2010; Wilson, Osterhaus, Farris, Doucette, Currie, Bullock, and Kumbera 2005). The sensitivity analysis involved altering elements of the original calculation of the service such as the staff member delivering the service (from the pharmacist to the technician or student) using different models of calculation, using different rates of wages and altering patient payment. This resulted in a mixed result of net loss and profit for some services being reported(Kent, McDonough, Dinges, and Doucette 2006; McDonough, Harthan, McLeese, and Doucette 2010). 
McDonough et al. (2010) reported for 191 MTM services delivered in a pharmacy over 16 months a net profit of $\$ 3.72$ when the MTM service was delivered with a standard pharmacist wage of $\$ 1.24 /$ minute and a net profit of $\$ 7155.18$ if a student pharmacist delivered the majority of the service with the pharmacist spending 15 minutes checking the students work(McDonough, Harthan, McLeese, and Doucette 2010). However, a net loss was reported in the same study when the pharmacist delivered the MTM service (see Net Loss section). Kent et al. (2006) calculated a mixture of net profit and loss for a blood pressure monitoring service delivered 528 times in one pharmacy over 24 months. With a pharmacist delivering the service a net loss of $\$ 1576.39$ was generated, while a resident providing the service generated a net gain of $\$ 136.95$ and a combination of pharmacist and resident providing the service saw a net loss of \$719.72(Kent, McDonough, Dinges, and Doucette 2006).

Net Loss

Three papers reported a net loss for a number of professional services including blood pressure testing, glycosylated haemoglobin testing, bone mineral density (BMD) testing, total cholesterol/blood glucose testing, total cholesterol/high density lipoprotein cholesterol testing, alanine aminotransferase testing, pneumococcal vaccination, Doc-U-Dose service, medication planning service, bubble pack service, cholesterol screenings and medication therapy management (MTM) services(Doucette, McDonough, Mormann, Vaschevici, Urmie, and Patterson 2012; Kent, McDonough, Dinges, and Doucette 2006; McDonough, Harthan, McLeese, and Doucette 2010). Net loss reported in Doucette et al. (2012) ranged between negative $\$ 6.77$ in a year for a pneumococcal vaccination service delivered to 9 patients in one pharmacy, and negative $\$ 8819.66$ in a year for a Doc-U-Dose service delivered 32 times in one pharmacy(Doucette, McDonough, Mormann, Vaschevici, Urmie, and Patterson 2012). Similarly Kent et al. (2006) reported a net loss which ranged between negative $\$ 64.04$ with a resident providing a total cholesterol/blood glucose testing service delivered 59 times in one pharmacy over 24 months, to negative $\$ 1576.39$ with a pharmacist 
providing a blood pressure testing service delivered 528 times in one pharmacy over 24 months(Kent, McDonough, Dinges, and Doucette 2006). Net losses of $\$ 1946.88$ and $\$ 1817.83$ were reported in McDonough et al. (2010) for 191 MTM services delivered over 16 months in a pharmacy when a higher wage of $\$ 1.47 /$ minute for the pharmacist or additional pharmacist training was included in the costs respectively(McDonough, Harthan, McLeese, and Doucette 2010). One paper concluded that the costs greatly exceeded the revenue for a men's health risk assessment service delivered 382 times between 30 pharmacies in 12 weeks, however no calculation or value for net loss was reported(Boyle, Coffey, and Palmer 2004).

Model to financially assess professional services

A model comprised of the key financial elements identified in this systematic review is outlined in Figure 2. There are three major elements to the model: implementation stage as defined by Moullin et al. (2016) (see Methods section), financial measures and performance indicators. The financial measures are costs, revenues and breakeven point. In the first phase, the breakeven point is forecasted based on the costs and revenue of the service. Costs include both initial, ongoing and direct sources of revenue are measured due to the early stages of implementation. This leads onto the calculation of performance indicators to further evaluate the service. In the first phase, return on investment (ROI) which incorporates net profit or loss, is included in the model. At the maintenance or sustainability stages the service is well integrated into the pharmacies daily activities and therefore secondary sources of revenue such as companion sales should be included. The ROI and net profit or loss of the service is assessed based on the cost and revenue

Figure 2

Model of financial measures and performance indicators used to assess professional services in community pharmacy.

\section{Discussion}


This systematic review gathers the available evidence addressing the financial analysis of professional services delivered in community pharmacy from the business perspective. Within the 21 studies identified, key measures and indicators used to financially assess services have been categorised and expanded to develop a model that will assist in streamlining practice and further research (figure 2). The findings of this review indicate that researchers are using a wide range of financial measures and different reporting systems making it difficult to compare results between studies. For example, many of the studies in this review did not report a comprehensive number of financial measures and performance indicators. Indirect variable and indirect semi-variable costs were not reported in any of the studies. Four studies drew conclusions about the financial performance of a professional service based upon revenue data alone(Houle, Chuck, and Tsuyuki 2012; Lasota 2015; Melody, Shah, Patel, and Willey 2015; Riley 2013) and 3 based on only cost data(Gregorio, Russo, and Lapao 2015; Lecher, Shrestha, Botts, Alvarez, Moore, Thomas, and Weidle 2015; Rupp 2011). It has been established that measuring all costs and revenue is crucial to managing a service and calculating its true value(Langfield-Smith 2015). Without all costs and revenue, performance indicators, such as $\mathrm{ROI}$, cannot be calculated and therefore an appropriate financial evaluation cannot be made(Langfield-Smith 2015). Only two studies reported the ROI of the professional services assessed, despite it being considered a vital indicator of performance for pharmacy managers when investing in implementing a service(Rhodes, Reynolds, Marciniak, and Ferreri 2013; Gazda, Berenbrok, and Ferreri 2016; Carroll 2007). Another potential reason why the remaining studies did not calculate $\mathrm{ROI}$ for their professional services is that the authors of these studies deemed drawing conclusions based on other financial measures was sufficient, such as costs, revenue or net profit/loss. Gazda et al. (2016) reported a positive ROI of 4.6 per cent for a Medication Therapy Management service(Gazda, Berenbrok, and Ferreri 2016). However, this may not be a sufficient ROI for some pharmacy business and investing in other services or activities may produce a more favourable return. The reported ROI in these studies may have implications on the implementation of professional service in community pharmacy. An adequate return on the 
investment may act as a facilitator to implementation, as pharmacy owners see a benefit in their financial investment. On the other hand, an inadequate return on the investment may act as a financial barrier for pharmacy owners. Future studies should report ROI in order to enable implementation of services allowing a more holistic financial appraisal of the service and may encourage implementation of professional services by pharmacy owners.

In this review, seven studies that investigated a service at the sustainability stage of implementation were identified, and of these only one reported ROI(Doucette, McDonough, Mormann, Vaschevici, Urmie, and Patterson 2012; Gazda, Berenbrok, and Ferreri 2016; Gregorio, Russo, and Lapao 2015; Kent, McDonough, Dinges, and Doucette 2006; Liu, Nevins, Carruthers, Doucette, McDonough, and Pan 2007; McDonough, Harthan, McLeese, and Doucette 2010; Rupp 2011). The sustainability stage is critical for pharmacy owners and managers when deciding to continue delivering a professional service, as it demonstrates the nature of the service when completely integrated into daily practice(Moullin, Sabater-Hernandez, and Benrimoj 2016). A lack of studies at the sustainability stage may be due to the fact that many community pharmacies have not been providing professional services for a long period of time. However as community pharmacies continue to deliver these services the financial implications become more critical.

In addition to identifying the financial measures used to assess services, the current review highlights the different units of analysis used. The variety of units of analysis used has reduced the ability to compare results (Rhodes, Reynolds, Marciniak, and Ferreri 2013; Doucette, McDonough, Mormann, Vaschevici, Urmie, and Patterson 2012; Gazda, Berenbrok, and Ferreri 2016; Houle, Chuck, and Tsuyuki 2012; Lasota 2015; McDonough, Harthan, McLeese, and Doucette 2010; Melody, Shah, Patel, and Willey 2015; Riley 2013; Rupp 2011; Pudlo 2011). For instance, labour costs for a Medication Therapy Management service were reported by Rupp et al. (2011) per unit of service delivered, while Gazda et al. (2016) calculated the total cost of labour over a 12 month period. Future research into implementing standardised units of measurement are needed, as they will 
improve comparability of results between studies and make it easier to judge the viability of providing services in community pharmacies from a business perspective.

Interestingly, some studies reported a net loss on provision of services(Doucette, McDonough, Mormann, Vaschevici, Urmie, and Patterson 2012; Kent, McDonough, Dinges, and Doucette 2006; McDonough, Harthan, McLeese, and Doucette 2010). A contributing factor to this is the reported inadequate reimbursement by government or third-party payers(Rhodes, Reynolds, Marciniak, and Ferreri 2013; Boyle, Coffey, and Palmer 2004; Kent, McDonough, Dinges, and Doucette 2006; McDonough, Harthan, McLeese, and Doucette 2010). This was apparent in Doucette et al. (2012) where an increase in the cost of the pneumococcal vaccination without a compensatory increase in reimbursement, saw a net loss reported for the service in 2009 and 2010, whilst it previously had generated a net profit in 2008(Doucette, McDonough, Mormann, Vaschevici, Urmie, and Patterson 2012). Other factors implicated in a net loss include increases in labour costs or additional training, which have been examined in some studies using a sensitivity analysis(Cerulli, and Zeolla 2004; Hedden, Kuehl, and Liu 2014; Kent, McDonough, Dinges, and Doucette 2006; McDonough, Harthan, McLeese, and Doucette 2010; Wilson, Osterhaus, Farris, Doucette, Currie, Bullock, and Kumbera 2005). Clearly, any change to costs or revenue may affect the overall financial outcome of a service. Therefore, ongoing monitoring of services is critical and has been included in the model for professional service assessment developed in this study (see Figure 2). While most of the services in the studies were government funded(Rhodes, Reynolds, Marciniak, and Ferreri 2013; Boyle, Coffey, and Palmer 2004; Gazda, Berenbrok, and Ferreri 2016; Houle, Chuck, and Tsuyuki 2012; Kent, McDonough, Dinges, and Doucette 2006; Liu, Nevins, Carruthers, Doucette, McDonough, and Pan 2007; McDonough, Harthan, McLeese, and Doucette 2010; Riley 2013; Pudlo 2011; Rieck 2006), 4 studies reported reimbursement by insurance companies, which highlights an alternative potential source of revenue for pharmacists to seek(Lasota 2015; Melody, Shah, Patel, and Willey 2015; Wilson, Osterhaus, Farris, Doucette, Currie, Bullock, and Kumbera 2005; Wood, McDonough, and Doucette 2009). 
Along with the measures and indicators employed to financially assess services, the data collection methods employed in each study have also been taken into account in this review. As with the financial assessment methods, data collection methods were also inconsistent across studies. For instance, in some studies labour costs were estimated via the provider self-recording the time to deliver the service(Hedden, Kuehl, and Liu 2014; Wood, McDonough, and Doucette 2009). This method of data collection introduces a source of bias to the results whereby pharmacists over or under estimate the time to provide a service. This bias can be overcome by employing a trained observer to measure the time taken to deliver the service as seen in Gregorio et al. (2015). Additionally, integrating the concepts in the model (figure 2 ) into the routine monitoring of the financial performance, may improve the accuracy of reporting indicators. This will be valuable not only for pharmacy owners but also researches to improve reliability of results.

Amongst the vast array of professional services literature, only a relatively small number of studies address the financial aspects of professional services in the community pharmacy setting. This may be due to the lack of interest in professional services from the pharmacy business perspective. Actually, the majority of research is more focussed on patient, pharmacist, or system wide economic outcomes (Cranor, Bunting, and Christensen 2003; Cranor, and Christensen 2003; Jodar-Sanchez, Malet-Larrea, Martin, Garcia-Mochon, Lopez Del Amo, Martinez-Martinez, Gastelurrutia-Garralda, Garcia-Cardenas, Sabater-Hernandez, Saez-Benito, and Benrimoj 2015; Machado, Bajcar, Guzzo, and Einarson 2007). More research into the financial performance of professional services for the pharmacy business is necessary to ensure the financial sustainability of services in practice. Furthermore, increased awareness of the financial advantages of such services may improve the uptake of services by pharmacists. It is important to note that the majority of studies conducted in this area and reviewed here are from the USA, despite professional services being delivered in many countries around the world(Houle, Grindrod, Chatterley, and Tsuyuki 2014). The types of services and conditions under which these studies have been financially assessed are therefore oriented toward the USA, which limits their international scope. Variations in 
remuneration structures of services are evident, for example reported revenue from insurance companies is evident in the USA but not employed in other countries. Additionally due to the deregulation of ownership of pharmacies in the USA, the types of business models are much more diverse, with large corporate chains dominating the landscape which is not as common in countries such as Australia and within Europe where pharmacy ownership remains regulated.

\section{Conclusion}

A limited number of studies, with differing methodologies, that financially assess professional services in community pharmacy have been identified that. The findings of this review indicate that researchers are using a wide range of financial measures and different reporting systems, hindering the ability to compare results between studies. The model proposed provides a structured approach for pharmacists to overcome barriers to implement services and manage their financial performance. It offers a holistic financial assessment of professional services and promotes further research in the field, which is currently lacking.

\section{Bibliography}

Hindle, K; Neil, C (2002). "Can Applied Entrepreneurship Education Enhance Job Satisfaction and Financial Performance? An Empirical Investigation in the Australian Pharmacy Profession," Journal of Small Business Management 40(2), 162-167.

Singleton, J. A. and Nissen, L. M. (2014). "Future-Proofing the Pharmacy Profession in a Hypercompetitive Market," Res Social Adm Pharm 10(2), 459-68.

Roberts, A. S., Benrimoj, S. I., Chen, T. F., Williams, K. A., Hopp, T. R. and Aslani, P. (2005). "Understanding Practice Change in Community Pharmacy: A Qualitative Study in Australia," Res Social Adm Pharm 1(4), 546-64.

Rotta, I., Souza, T. T., Salgado, T. M., Correr, C. J. and Fernandez-Llimos, F. (2016). "Characterization of Published Randomized Controlled Trials Assessing Clinical Pharmacy Services around the World," Res Social Adm Pharm.

Rhodes, S. A., Reynolds, A. E., Marciniak, M. W. and Ferreri, S. P. (2013). "Evaluating the Economic Impact of a Targeted Medication Intervention Program," J Pharm Pract 26(6), $562-73$. 
Rogoff, E.G, Lee, M.S and Suh, D.C (2004). ""Who Done It?" Attributions by Entrepreneurs and Experts of the Factors That Cause and Impede Small Business Success," Journal of Small Business Management 42(4), 364-376.

Houle, S. K., Grindrod, K. A., Chatterley, T. and Tsuyuki, R. T. (2014). "Paying Pharmacists for Patient Care: A Systematic Review of Remunerated Pharmacy Clinical Care Services," Can Pharm J (Ott) 147(4), 209-32.

Moullin, J. C., Sabater-Hernandez, D., Fernandez-Llimos, F. and Benrimoj, S. I. (2013). "Defining Professional Pharmacy Services in Community Pharmacy," Res Social Adm Pharm 9(6), 989-95.

Benrimoj, S. I., Feletto, E, Gastelurrutia, M. A., Martinez-Martinez, F. and Faus, M.J. (2010). "A Holistic and Integrated Approach to Implementing Cognitive Pharmaceutical Services," ARS Pharmaceutica 51(2), 69-87.

Cranor, C. W., Bunting, B. A. and Christensen, D. B. (2003). "The Asheville Project: LongTerm Clinical and Economic Outcomes of a Community Pharmacy Diabetes Care Program," J Am Pharm Assoc (2003) 43(2), 173-84.

Cranor, C. W. and Christensen, D. B. (2003). "The Asheville Project: Short-Term Outcomes of a Community Pharmacy Diabetes Care Program," J Am Pharm Assoc (Wash) 43(2), 149-59.

Jodar-Sanchez, F., Malet-Larrea, A., Martin, J. J., Garcia-Mochon, L., Lopez Del Amo, M. P., Martinez-Martinez, F., Gastelurrutia-Garralda, M. A., Garcia-Cardenas, V., SabaterHernandez, D., Saez-Benito, L. and Benrimoj, S. I. (2015). "Cost-Utility Analysis of a Medication Review with Follow-up Service for Older Adults with Polypharmacy in Community Pharmacies in Spain: The Consigue Program," Pharmacoeconomics 33(6), 599-610.

Machado, M., Bajcar, J., Guzzo, G. C. and Einarson, T. R. (2007). "Sensitivity of Patient Outcomes to Pharmacist Interventions. Part I: Systematic Review and Meta-Analysis in Diabetes Management," Ann Pharmacother 41(10), 1569-82.

Lounsbery, J. L., Green, C. G., Bennett, M. S. and Pedersen, C. A. (2009). "Evaluation of Pharmacists' Barriers to the Implementation of Medication Therapy Management Services," J Am Pharm Assoc (2003) 49(1), 51-8.

Elrod, S., Synder, M.E, Hall, D, Mcgivney, M.A.S and Smith, R.B (2012). "Practice Change in Community Pharmacy: A Case Study of Multiple Stakeholders' Perspectives," Innovations in Pharmacy 3(3), 82.

Boyle, T. C., Coffey, J. and Palmer, T. (2004). "Men's Health Initiative Risk Assessment Study: Effect of Community Pharmacy-Based Screening," J Am Pharm Assoc (2003) 44(5), 569-77.

Cerulli, J. and Zeolla, M. M. (2004). "Impact and Feasibility of a Community Pharmacy Bone Mineral Density Screening and Education Program," J Am Pharm Assoc (2003) 44(2), 161-7. 
Doucette, W. R., McDonough, R. P., Mormann, M. M., Vaschevici, R., Urmie, J. M. and Patterson, B. J. (2012). "Three-Year Financial Analysis of Pharmacy Services at an Independent Community Pharmacy," J Am Pharm Assoc (2003) 52(2), 181-7.

Gazda, N. P., Berenbrok, L. A. and Ferreri, S. P. (2016). "Comparison of Two Medication Therapy Management Practice Models on Return on Investment," J Pharm Pract.

Gregorio, J., Russo, G. and Lapao, L. V. (2015). "Pharmaceutical Services Cost Analysis Using Time-Driven Activity-Based Costing: A Contribution to Improve Community Pharmacies' Management," Res Social Adm Pharm.

Hedden, M. A., Kuehl, P. G. and Liu, Y. (2014). "Economic Analysis of a Herpes Zoster Vaccination Program in 19 Affiliated Supermarket Pharmacies," J Am Pharm Assoc (2003) 54(4), 390-6.

Houle, S. K., Chuck, A. W. and Tsuyuki, R. T. (2012). "Blood Pressure Kiosks for Medication Therapy Management Programs: Business Opportunity for Pharmacists," $J$ Am Pharm Assoc (2003) 52(2), 188-94.

Kent, K., McDonough, R. P., Dinges, B. and Doucette, W. R. (2006). "Retrospective Financial Analysis of Wellness Center from an Independent Community Pharmacy Perspective," J Am Pharm Assoc (2003) 46(4), 447-52.

Lasota, S.T; McConaha, J.L; Lynch, K.J; Greco, A.J (2015). "Implementation Strategy to Bring Medication Therapy Management into High-Volume Community Pharmacies," Am J Pharm Benefits 7(2), 92-99.

Lecher, S. L., Shrestha, R. K., Botts, L. W., Alvarez, J., Moore, J. H., Jr., Thomas, V. and Weidle, P. J. (2015). "Cost Analysis of a Novel Hiv Testing Strategy in Community Pharmacies and Retail Clinics," J Am Pharm Assoc (2003) 55(5), 488-92.

Liu, Y., Nevins, J. C., Carruthers, K. M., Doucette, W. R., McDonough, R. P. and Pan, X. (2007). "Osteoporosis Risk Screening for Women in a Community Pharmacy," J Am Pharm Assoc (2003) 47(4), 521-6.

McDonough, R. P., Harthan, A. A., McLeese, K. E. and Doucette, W. R. (2010).

"Retrospective Financial Analysis of Medication Therapy Management Services from the Pharmacy's Perspective," J Am Pharm Assoc (2003) 50(1), 62-6.

Melody, K. T., Shah, C. J., Patel, J. and Willey, V. J. (2015). "Implementation of a Student Pharmacist-Run Targeted Medication Intervention Program," J Pharm Pract.

Norwood, G. J., Sleath, B. L., Caiola, S. M. and Lien, T. (1998). "Costs of Implementing Pharmaceutical Care in Community Pharmacies," J Am Pharm Assoc (Wash) 38(6), 75561.

Riley, K. (2013). "Enhanced Medication Management Services in the Community: A WinWin Proposal from an Economic, Clinical and Humanistic Perspective," Can Pharm J (Ott) 146(3), 162-8. 
Rupp, M. T. (2011). "Analyzing the Costs to Deliver Medication Therapy Management Services," J Am Pharm Assoc (2003) 51(3), e19-26; quiz e27.

Wilson, J. B., Osterhaus, M. C., Farris, K. B., Doucette, W. R., Currie, J. D., Bullock, T. and Kumbera, P. (2005). "Financial Analysis of Cardiovascular Wellness Program Provided to Self-Insured Company from Pharmaceutical Care Provider's Perspective," J Am Pharm Assoc (2003) 45(5), 588-92.

Wood, H. M., McDonough, R. P. and Doucette, W. R. (2009). "Retrospective Financial Analysis of a Herpes Zoster Vaccination Program from an Independent Community Pharmacy Perspective," J Am Pharm Assoc (2003) 49(1), 12-7.

Pudlo, A; Abernethy, M; Peek, J (2011). "Financial Analysis of Mtm Services Implemented in a Non-Mtm Participating Pharmacy.," Community Pharmacy Foundation.

Rieck, A; Clifford, R; Everett, A (2006). "Community Pharmacy Weight Management Project," The University of Western Australia, 283.

Liberati, A., Altman, D. G., Tetzlaff, J., Mulrow, C., Gotzsche, P. C., Ioannidis, J. P., Clarke, M., Devereaux, P. J., Kleijnen, J. and Moher, D. (2009). "The Prisma Statement for Reporting Systematic Reviews and Meta-Analyses of Studies That Evaluate Health Care Interventions: Explanation and Elaboration," Ann Intern Med 151(4), W65-94.

Shea, B. J., Grimshaw, J. M., Wells, G. A., Boers, M., Andersson, N., Hamel, C., Porter, A. C., Tugwell, P., Moher, D. and Bouter, L. M. (2007). "Development of Amstar: A Measurement Tool to Assess the Methodological Quality of Systematic Reviews," BMC Med Res Methodol 7, 10.

Shemilt, I., Thomas, J. and Marcello, M. (2010). "A Web-Based Tool for Adjusting Costs to a Specific Target Currency and Price Year.," Evidence \& Policy 6(1), 51-59.

Langfield-Smith, K (2015). Management Accounting : Information for Creating and Managing Value North Ryde, NSW, Australia: McGraw-Hill Asutralia Pty Ltd.

Moullin, J. C., Sabater-Hernandez, D. and Benrimoj, S. I. (2016). "Model for the Evaluation of Implementation Programs and Professional Pharmacy Services," Res Social Adm Pharm 12(3), 515-22.

Carroll, N.V (2007). Financial Management for Pharmacists: A Decision-Making Approach. Baltimore, MD, USA: Lippincott Williams \& Wilkins. 
Table 1

Search strategies used in systematic review literature search.

\begin{tabular}{|l|l|}
\hline PubMed & $\begin{array}{l}\text { (("Community Pharmacy Services"[MH] OR “Pharmaceutical services" [TW] OR } \\
\text { pharmacies[TW] OR “Community Pharmacy" [TIAB]) AND ("financial } \\
\text { analysis"[TIAB] OR } \\
\text { profit*[TIAB] OR revenue*[TIAB] OR accounting[TIAB] OR profitability[TIAB] OR } \\
\text { "Reimbursement Mechanisms"[TW])) }\end{array}$ \\
\hline Scopus & $\begin{array}{l}\text { TITLE-ABS-KEY ("community pharmacy" OR "community pharmacies") AND } \\
\text { TITLE-ABS-KEY (economics OR "financial management" OR profit) }\end{array}$ \\
\hline
\end{tabular}


Table 2

Google Search: terms used in systematic review grey literature search.

\begin{tabular}{|l|l|l|}
\hline \multicolumn{1}{|c|}{ Financial Keywords } & \multicolumn{1}{|c|}{ Pharmacy Keywords } & \multicolumn{1}{c|}{ Filters } \\
\hline Financial Analysis & Community Pharmacy & filetype:(pdf) \\
Revenue & Professional Pharmacy Services & \\
Cost & Pharmaceutical Services & \\
\hline
\end{tabular}

